\title{
Collaborative Practices Among Australian School Psychologists, Guidance Officers and School Counsellors: Important Lessons for School Psychological Practice
}

\author{
Monica Thielking, Jason Skues and Vi-An Le \\ Department of Psychological Sciences, Swinburne University of Technology, Melbourne, Victoria, \\ Australia
}

In Australia, policies such as the Better Outcomes in Mental Health Care initiative have been the impetus for improved collaboration between medical practitioners and psychologists in general. However, policies that promote collaboration between school psychologists and community mental health, health, justice and/or human services professionals are yet to occur. This is despite known benefits arising from integrated service delivery to people with complex needs, including young people. School psychologists are an integral part of the service mix and are in an excellent position to promote collaborative practices and to assist students and families to navigate and access school-based and community-based support. This study, conducted in Queensland, Australia, investigated school psychologists', guidance officers' and school counsellors' current and preferred levels of collaboration, their perceptions of the drivers and barriers to collaborative practices, and their views on how collaborative practices affect students. Results revealed that participants engaged more fully in within-school collaboration than collaboration with professionals and agencies outside of the school; they had a desire to collaborate more fully both internally and externally; and that concerns regarding confidentiality, time restrictions, and lack of access to appropriate services can sometimes make collaboration and information sharing difficult. Implications for school psychological practice are discussed.

- Keywords: school psychology, collaboration, service integration, confidentiality, information sharing

Within a school context, teachers working together to meet student needs is commonplace, particularly among teachers delivering a coordinated curriculum (Hudson, 2012; Scruggs, Mastropieri, \& McDuffie, 2007) or devising strategies to deal with student behavioural issues (Safran \& Oswald, 2003). Alternatively, while it has been reported that school psychologists collaborate with teachers and other

Received 03 December 2017; Accepted 06 February 2018; First published online 10 April 2018

Address for correspondence: Dr Monica Thielking, Swinburne University of Technology, Faculty of Health, Arts and Design, Department of Psychological Sciences, Mail H99, PO Box 218, Hawthorn VIC 3122, Australia. Email: mthielking@swin.edu.au. 
professionals both within and outside of a school setting, research on the mechanisms of school psychologist collaboration is scarce. What we do know is that teachers and principals often desire the school psychologist to engage in more information sharing, but that this can place a school psychologist in a tricky ethical and professional dilemma (see Thielking \& Jimerson, 2006). Such competing demands for information from a range of stakeholders has been aptly described as a 'complex balancing act' (Glosoff \& Pate, 2002). Furthermore, as mental health issues in young Australians continue to be a national concern (Lawrence et al., 2015), there is a greater demand placed on schools for school-led interventions that involve multiple and integrated services. The degree to which school psychologists engage in multidisciplinary and integrated practices in schools, and the mechanisms of effective collaborative practice, which is now considered to be the gold standard of service delivery in the public youth mental health domain (i.e., Scott et al., 2009), is the focus of this article.

In multidisciplinary agencies, service integration is typically defined as 'the coming together of individuals to work in concerted effort to achieve common goals' (Keast, Brown, \& Mandell, 2007, p. 9). In the mental health domain, it is the opposite of 'fragmented and disjointed' care among mental health professionals (Hickie \& Groom, 2002 , p. 377). In school psychology, a common goal may well be 'to support students to achieve academic success, psychological health, and social and emotional wellbeing' (Australian Psychological Society, 2016, p. 5). As a theoretical construct, service integration is not binomial. That is, services or professionals are not judged as being integrated or non-integrated. Rather, service integration exists along a continuum from low to high intensity, and where a service sits on this continuum is dependent on a combination of factors, including the needs of the agency, professionals and/or client/s.

Keast et al. (2007) argued that integration is operationalised by the three 'Cs' cooperation, coordination and collaboration - terms that have commonly been used interchangeably but that are each, in and of themselves, unique aspects of 'horizontal' or intra/interagency integration that function with differing intensity. In other work on this topic, Browne et al. (2004) developed the Human Services Integration Measure to assess the extent (the identification and number of services within a selection of programs or sectors involved in a partnership), scope (the number of services in a network that have some awareness of or link with other services), and depth (the depth of links among all services in a network) of integration within a network of services. In an Australian study that utilised this measure in the health, homelessness and mental health sectors, the better the quality of relationships among multidisciplinary stakeholders (i.e., improved depth) the better the self-reported client outcomes (Flatau et al., 2013).

In Australia and internationally, the move towards better connected and fewer siloed services has been largely driven by government policy initiatives that aim to streamline services, reduce duplication of service provision, and ensure clients have all of their needs identified and supported earlier rather than later. An example of this is the 'Better Outcomes in Mental Health Care' initiative, which systematically promotes the integration of medical and psychological services in the care of patients (Hickie \& Groom, 2002). A component of this policy is the Access To Allied Psychological Services (ATAPS) program, which 'supports GPs and psychologists to work together to provide optimal mental health care' (Pirkis et al., 2006, p. 152). 
An online survey of Australian Psychological Society (APS) members' experiences of ATAPS found that of the 248 psychologists who responded, better relationships with general practitioners (GP), an increased referral base, and an appreciation of having an overarching framework to guide the structure of service delivery were three key reported advantages of the ATAPS program (Pirkis et al., 2006). This is consistent with service integration research, which shows that for effective integration to occur there is a need for a guiding framework that legitimises such a model of practice (Keast et al., 2007). ATAPS is well utilised, with 20,156 young people aged 12-25 years accessing support under this scheme in the period from 1 July 2009 to 30 June 2012, with significant improvement in mental health outcomes reported (Bassilios, Rickwood, Pirkis, Spittal, \& Telford, 2017). Furthermore, the headspace National Youth Mental Health Foundation, which is also well utilised by Australian youth (Bassilios et al., 2017), has recently created co-located (school- and headspace-based) 'headspace school psychologists' positions, showing that there is a move towards creating a more collaborative mental health service for school students that encompasses the services of psychologists and their colleagues from both local health services and schools. What is yet to occur, however, is a national framework guiding the structure of collaborative service delivery for school- or department-employed, or even independently contracted, school psychologists.

There is also a noted dearth of Australian and international research focusing on integrated and multidisciplinary youth mental health service delivery (Kinchin, Tsey, Heyeres, \& Cadet-James, 2016). There is a gap in studies that explore the mechanisms or the how of integrated mental health interventions for children and young people in both community and school settings, and this is especially the case in relation to interventions provided by school psychologists. Importantly, while we know that school psychologists engage in collaborative practice and face administrative pressure to share student information with others (i.e., Bell \& McKenzie, 2013), there is a lack of studies that explore the extent of school psychologist collaboration specifically. A recent systematic review of the integration literature related to youth mental health in Australia and internationally, conducted by Kinchin et al. (2016), found only one Australian study that evaluated the effectiveness of integrated youth mental health services; however, school mental health services were absent from the mix (see Scott et al., 2009). Understanding the drivers of and barriers to collaboration in the school context is vitally important in order to support school-based professionals in working effectively with the vast array of stakeholders that surround many of their student clients who are presenting with multiple needs.

\section{Drivers Of and Barriers to Inter-Service Collaboration}

In Australia, school psychologists have a wide range of roles that can be influenced by employment conditions and available resources (such as time). School psychologists' roles may include prevention (e.g., health promotion), assessment (e.g., diagnosis), intervention (e.g., counselling), collaboration (e.g., external consultations and referral) and/or management (e.g., administration and supervision) (Campbell \& Colmar, 2014). In the school context, a collaborative approach has mostly been promoted for at-risk students with complex or 'multi-service' needs (i.e., Adelman \& Taylor, 
2002; Gerry \& Paulsen, 1995). For many at-risk children and young people, a range of services is often required to address their complex needs (Power, Whitty, \& Youdell, 1999). Oftentimes, schools alone lack the appropriate resources to provide such an array of services, highlighting the potential benefits of an integrated services approach to providing holistic care (Gilligan, 1998; McArthur, Thomson, Winkworth, \& Butler, 2009). That said, timely and coordinated support is only feasible if school, community, and family resources are deliberately woven together, and structures are in place to support this network of services (Adelman \& Taylor, 2002; Nicholson, Artz, Armitage, \& Fagan, 2000).

In general, the drivers of successful collaboration are categorised into agency forces (such as leadership and motivation) and structural forces (such as available economic resources and organisational culture; William \& Sullivan, 2009). Alternatively, noted barriers to deep collaboration include poor relationships between staff, little or no awareness of the other service, and low interagency functioning (Flatau et al., 2013). Entrenched behaviours related to specialist services and service domain 'silos' is also a reported barrier against effective collaboration (Goodwin, 2008; Grone \& GarciaBarbero, 2002). The authors would also argue that discipline-specific drivers may come into play in relation to the extent of interdisciplinary and interagency collaboration. For example, a qualitative study of American school counsellors' experiences of collaboration with a local youth mental health service showed mixed findings in relation to counsellors' willingness to collaborate due to, among other things, concerns surrounding maintaining confidentiality, professional responsibility, and student consent issues (Hobbs \& Collison, 1995). Taken together, these findings imply that effective collaboration within schools and between schools and external services would require leadership, open-mindedness, a reinterpretation of the 'context' of school psychological services, and the establishment of systems or frameworks that help to promote collaboration and cooperation in a deliberate and structured way that recognises the unique ethical responsibilities of school psychologists within the broader professional services mix.

Despite the known benefits of 'working together' to meet students' mental health and other needs, one possible barrier to collaboration may be a careful avoidance on the part of school psychologists to not engage in professional practices that may undermine their ethical and legal duty of care to ensure client confidentiality and privacy (i.e., as specified in the Health Records Act 2001; National Privacy Principles of the Privacy Act 1988; and the profession's Code of Ethics, Australian Psychological Society, 2007), and in addition to professional responsibilities, a school psychologist's contractual or employment obligations may also play a role here. That is, how confident do school psychologists feel about sharing information about student clients or even issues facing a particular school population with others? How much does the adage 'what happens in the school stays in the school' apply to this particular school-based mental health service? Finally, the actual and perceived confidentiality of a service is a crucial component of student help-seeking behaviour (Campbell \& Colmar, 2014; Reid, 1996), with many studies showing that students highly value a confidential school counselling service. How much does this factor feature in school psychologists' decisions to collaborate or not collaborate in order to ensure that this perception is upheld and maintained? What pressures do school psychologists face in balancing between maintaining confidentiality and collaborating with others to meet students' needs? 


\section{Research Aims}

The present study had the following aims: (1) to investigate the actual and preferred depth of collaboration within a sample of Australian school psychologists, guidance officers and school counsellors using an adapted version of the 'depth of integration' component of Browne et al.'s (2004) Human Services Integration Measure; and (2) to seek qualitative feedback from participants about: (a) the main drivers and barriers to collaborative practice, (b) the perceived impact of collaborative practice on student outcomes, and (c) the key ingredients of collaborative practice in the context of school psychology and school counselling.

\section{Method}

Procedure

Approval to conduct the study was obtained from the relevant Human Research Ethics Committee. The present study took place in 2015 at a school counselling conference in Queensland (unnamed to protect the privacy and anonymity of participants). Participants were recruited via email that contained a link to the anonymous online survey prior to conference attendance.

\section{Sample Characteristics}

A sample of convenience (school counselling conference) was utilised to investigate and inform school psychologist collaboration practices. Various titles are used to describe the role of school psychologists, and in Queensland 'guidance officer' has commonly been used for those with Australian Health Practitioner Regulation Agency (AHPRA) registration (Faulkner \& Jimerson, 2017). It was communicated to the author that the majority of delegates were registered psychologists by the conference organisers. However, it is not entirely clear whether all participants were AHPRA registered, as 11 participants listed their role title as 'guidance officer', 20 as 'school counsellor', and 11 as 'school psychologist'. This may reflect the shift in the use of the 'euphemistic' guidance officer term to a more official designated term of school psychologist (Faulkner \& Jimerson, 2017). For the unique purpose of this study, the inclusion of both school counsellors and guidance officers (who may or may not be psychologists) in data analysis was deemed acceptable as titles are used interchangeably, and although important differences between the professions exist, school counsellors and psychologists deal with a range of student issues that may require a mixed-service response, as evidenced in Campbell and Colmar's (2014) description of Australian counsellors' and psychologists' roles. In the interests of brevity and to ensure an accurate representation of the sample, 'psychologists and counsellors' will be employed to describe the sample going forward.

The sample consisted of 42 school psychologists and counsellors working across three Australian education sectors (government $=3$; Catholic $=24$; and independent $=12$ ). Three participants did not reveal their school sector.

Two participants did not respond to any demographic questions. Of those who responded, 22 operated in metropolitan regions, while 18 worked in regional areas. Seventy-four percent were female and $22 \%$ were male, which reflects the gender distribution in this profession (Faulkner \& Jimerson, 2017). Most respondents worked with secondary school-aged students (57\%), six worked with primary school-aged students (14\%), and eight respondents were working with both age groups (19\%). 
Additionally, two participants worked with primary, secondary and preschool-aged students $(5 \%)$. The majority $(n=30)$ of the respondents worked for one school only, seven participants worked for two schools concurrently, two respondents worked for five schools, and one respondent worked for three schools. Sixty-seven percent worked full time and 31\% worked part-time. With regard to the school psychologist/counsellor to student ratio, $38 \%$ reported one school psychologist to 500 or 600 students; $24 \%$ reported one school psychologist to 700 or 900 students; $14 \%$ reported a ratio between one to 200 or 400 students; and 10\% reported one psychologist to 1,000 students. One respondent had a school psychologist/counsellor to student ratio of one to 30 . Five participants did not provide a response.

\section{Materials}

The School Counsellors and Collaboration Survey was designed specifically for this study and utilised both checklist and open-ended questions. A brief survey, which adapted the key components of the depth of integration scale in Browne et al.'s (2004) Human Services Integration Measure and was applied to a school psychology and counselling context, was constructed. The term 'collaboration' was used instead of 'integration', as it was decided that in an Australian school context, 'integration' is often associated with educational service provision for students with disabilities and may be misunderstood. The term 'school counsellor' was also employed to encompass the varying role titles of school psychologists, guidance officers and other role titles used in this area of practice.

Current depth of collaboration. To measure the depth of integration that school psychologists and counsellors engaged in, respondents were asked to rate the level to which they collaborated with professionals or services within and outside of a school on a scale ranging from 1 to 5 , with 1 indicating no collaboration, $2=$ an awareness level, $3=$ communication level, $4=$ cooperation level, $5=$ full collaboration. A non-applicable option (6) was provided for those who believed the listed service or professional was not applicable to their current work setting (see Table 1).

Preferred depth of collaboration. To measure the preferred depth of integration that school psychologists and counsellors believe they should engage in, respondents were asked to rate the extent to which they should collaborate with professionals or services within and outside of a school on a scale ranging from 1 to 5, with 1 indicating no collaboration, $2=$ an awareness level, $3=$ communication level, $4=$ cooperation level, $5=$ full collaboration. Again, a non-applicable option (6) was provided for those who believed the listed service or professional was not applicable to their current work setting (see Table 2).

Lastly, the survey included four open-ended questions that asked school psychologists and counsellors to share their experiences and attitudes towards collaboration in schools. These included: (1) Choose a service or professional that you fully collaborate with. What are the factors or features of this relationship that make this collaboration work? (2) Now choose a service or professional that you do not or only slightly collaborate with but for which you should collaborate with at a higher level. What are the barriers that are stopping you from collaborating with this professional or service? (3) In your opinion, what do you believe are the impacts on student outcomes when school counselling services work more collaboratively with other professionals and 
TABLE 1

The Percentage Depth to Which School Psychologists and Counsellors Collaborate With Others

\begin{tabular}{|c|c|c|c|c|c|c|}
\hline \multirow[b]{2}{*}{ Type of collaboration } & \multicolumn{6}{|c|}{ Level of collaboration (depth) } \\
\hline & 1 & 2 & 3 & 4 & 5 & 6 \\
\hline \multicolumn{7}{|l|}{ Internal to school or education department } \\
\hline Principal & 2.4 & 17.1 & 31.7 & 29.3 & 19.5 & - \\
\hline School leadership & 2.4 & 7.3 & 26.8 & 34.1 & 29.1 & - \\
\hline Year level coordinator & 2.5 & 7.5 & 22.5 & 32.5 & 27.5 & 7.5 \\
\hline Other school psychologist/counsellor & - & 15.0 & 7.5 & 10.0 & 42.5 & 25.0 \\
\hline Teacher & 2.5 & 7.5 & 52.5 & 22.5 & 15.0 & - \\
\hline School chaplain & 5.0 & 22.5 & 15.0 & 25.0 & 5.0 & 27.5 \\
\hline School nurse & 5.1 & 7.7 & 15.4 & 7.7 & 5.1 & 59.0 \\
\hline Student welfare coordinator & 4.9 & 7.3 & 14.6 & 14.6 & 24.4 & 34.1 \\
\hline School wellbeing and support team & - & 9.8 & 14.6 & 26.8 & 29.3 & 19.5 \\
\hline School social worker & 12.2 & - & 4.9 & 4.9 & 4.9 & 73.2 \\
\hline Aide or student support teacher & 2.4 & 12.2 & 31.7 & 26.8 & 26.8 & - \\
\hline Departmental or Diocese support staff & 15.4 & 10.3 & 25.6 & 20.5 & 12.8 & 15.4 \\
\hline \multicolumn{7}{|l|}{ Local agency or professional external to school } \\
\hline Child/youth mental health service & - & 34.1 & 39.0 & 17.1 & 7.3 & 2.4 \\
\hline Youth homelessness service & 25.0 & 32.5 & 10.0 & 10.0 & 2.5 & 20.0 \\
\hline General practitioner/paediatrician/health service & 7.3 & 41.5 & 24.4 & 22.0 & 2.4 & 2.4 \\
\hline Private practising psychologist & 7.3 & 26.8 & 34.1 & 24.4 & 2.4 & 4.9 \\
\hline Hospital child/youth mental health service & 7.3 & 29.3 & 22.0 & 22.0 & 12.2 & 7.3 \\
\hline Child protection service & 4.9 & 14.6 & 39.0 & 29.3 & 12.2 & - \\
\hline Cultural or Indigenous service & 14.6 & 26.8 & 14.6 & 14.6 & 12.2 & 17.1 \\
\hline
\end{tabular}

Note: 1 = No collaboration, 2 = Awareness level, 3 = Communication level, 4 = Cooperation level, $5=$ Full collaboration,

$6=$ Percentage of respondents who believed that the choice of collaborator was not applicable. Bold type indicates most common response for each type of collaboration.

services? (4) Is there anything that school counsellors need to be particularly mindful of when working in a collaborative way with other services or professionals to support students?

\section{Results}

A non-experimental, cross-sectional research design was used to address the research questions. Quantitative data were analysed using SPSS Version 24.0. In order to address the first two research questions, both descriptive and inferential statistics were conducted and reported for each of the scales. These descriptives can be seen in Table 1 and Table 2 respectively. Moreover, inferential statistics (i.e., chi-square tests) were used to examine individual item responses and overall collaboration scores across sex, age group, age of students, role description, school sector, length of time working as a school psychologist/counsellor, number of schools in which the school psychologist/counsellor works, the ratio of school psychologists/counsellors to students, and whether they worked full time or part time.

As can be seen from Table 1, with the exception of the school nurse, student welfare coordinator, school social worker and school chaplain, where the most common response was 'not applicable', within the school context, most respondents were communicating, cooperating, or fully collaborating with other within-school professionals. The vast majority of school psychologists/counsellors collaborated at the 
TABLE 2

The Percentage Depth to Which School Psychologists and Counsellors Prefer to Collaborate With Others

\begin{tabular}{|c|c|c|c|c|c|c|}
\hline \multirow[b]{2}{*}{ Type of collaboration } & \multicolumn{6}{|c|}{ Preferred level of collaboration (depth) } \\
\hline & 1 & 2 & 3 & 4 & 5 & 6 \\
\hline \multicolumn{7}{|l|}{ Internal to school or education department } \\
\hline Principal & - & - & 18.4 & 42.1 & 39.5 & - \\
\hline School leadership & - & - & 18.4 & 36.8 & 42.1 & 2.6 \\
\hline Year level coordinator & - & - & 5.1 & 41.0 & 41.0 & 12.8 \\
\hline Other school psychologist/counsellor & - & - & 2.6 & 21.1 & 50.0 & 26.3 \\
\hline Teacher & - & 7.7 & 20.5 & 46.2 & 25.6 & - \\
\hline School chaplain & - & 5.3 & 26.3 & 31.6 & 10.5 & 26.3 \\
\hline School nurse & - & 7.7 & 12.8 & 15.4 & 7.7 & 56.4 \\
\hline Student welfare coordinator & - & 2.6 & 15.4 & 12.8 & 30.8 & 38.5 \\
\hline School wellbeing and support team & - & - & 5.4 & 27.0 & 51.4 & 16.2 \\
\hline School social worker & - & 5.3 & 5.3 & 7.9 & 15.8 & 65.8 \\
\hline Aide or student support teacher & 2.6 & - & 18.4 & 28.9 & 50.0 & - \\
\hline Departmental or Diocese support staff & - & 2.8 & 13.9 & 36.1 & 25.0 & 22.2 \\
\hline \multicolumn{7}{|l|}{ Local agency or professional external to school } \\
\hline Child/youth mental health service & - & 5.4 & 18.9 & 45.9 & 29.7 & - \\
\hline Youth homelessness service & - & 17.9 & 15.4 & 35.9 & 10.3 & 20.5 \\
\hline General practitioner/pediatrician/health service & - & 5.1 & 46.2 & 35.9 & 7.7 & 5.1 \\
\hline Private practising psychologist & - & 5.3 & 34.2 & 34.2 & 23.7 & 2.6 \\
\hline Hospital child/youth mental health service & - & 2.6 & 28.2 & 35.9 & 25.6 & 7.7 \\
\hline Child protection service & - & 2.6 & 23.1 & 43.6 & 30.8 & - \\
\hline Cultural or Indigenous service & 2.6 & 7.9 & 21.1 & 34.2 & 21.1 & 13.2 \\
\hline
\end{tabular}

Note: 1 = No collaboration, 2 = Awareness level, 3 = Communication level, 4 = Cooperation level, 5 = Full collaboration, $6=$ Percentage of respondents who believed that the choice of collaborator was not applicable. Bold type indicates most common response for each type of collaboration.

'communication' level with teachers and at the 'cooperation' level with another school psychologist/counsellor. In contrast, depth of integration with professionals external to the school was limited to mainly an 'awareness' and 'communication' level only.

Table 2 shows that most respondents preferred to be collaborating at a deeper 'cooperating and collaborating' level with other professionals within the school. In order of preference, the largest proportion of school psychologists/counsellors believed that they should fully collaborate with the school wellbeing and support team, aide or student support teacher, other school psychologists/counsellors, school leadership, and the year level coordinator. However, the majority of participants believed that collaborating with the school nurse, student welfare coordinator or the school social worker was not applicable to their school situation. For those who did believe it was applicable to collaborate with these latter professionals, most respondents preferred to be collaborating fully with the school welfare coordinator. Interestingly, most respondents preferred to be collaborating at the 'communicating' and 'cooperating' level with external professionals.

Individual Item Analysis Across Demographics

An analysis of the individual items revealed the level to which school psychologists/counsellors collaborated with their principal was significantly associated with school sector, $\chi 2(8)=16.91, p=.031$, length of time working as school 
psychologists/counsellors, $\chi 2(16)=35.33, p=.004$, the number of schools school psychologists/counsellors work in, $\chi 2(12)=28.21, p=.005$, and whether school psychologists/counsellors work full time or part time, $\chi 2(4)=12.43, p=.014$. In particular, school psychologists/counsellors collaborated more fully with principals in Catholic schools compared with independent or government schools. They also collaborated more with the principal when they were more experienced, worked in fewer schools, and when they worked full time.

The extent to which school psychologists/counsellors collaborated with year level coordinators was significantly associated with the age of students, $\chi 2(12)=27.18$, $p=.007$, the role description of the school psychologist/counsellor, $\chi 2(15)=36.02$, $p=.002$, and the number of schools the school psychologist/counsellor works in, $\chi 2(12)=33.36, p=.001$. School psychologists/counsellors collaborated more fully when dealing with both primary and secondary students or secondary students only compared with primary school students only or preschool students. Again, school psychologists/counsellors who worked in fewer schools tended to collaborate more with year level coordinators.

The level to which school psychologists/counsellors collaborated with other school psychologists/counsellors was significantly associated with what geographic region the school psychologists/counsellors worked in, $\chi 2(4)=9.70, p=.046$. That is, school psychologists/counsellors who worked in metropolitan areas tended to collaborate more fully with other school psychologists/counsellors than those who worked in regional areas. Moreover, school psychologists/counsellors were more likely to collaborate with teachers more fully if they were working in a Catholic school compared with independent and government schools, $\chi 2(8)=15.52, p=.050$.

The level to which school psychologists/counsellors collaborated with social workers was significantly associated with school sector, $\chi 2(8)=20.07, p=.008$, the age of students, $\chi 2(12)=54.50, p<.001$, and how many schools the school psychologist/counsellor works in, $\chi 2(12)=34.88, p<.001$. In particular, school psychologists/counsellors who worked in Catholic schools collaborated more with social workers than independent and government schools. Moreover, there appeared to some, albeit limited, collaboration with social workers for primary school students only, though most believed that collaborating with social workers was not applicable. School psychologists/counsellors also collaborated more fully when working in fewer schools.

The extent to which school psychologists/counsellors collaborated with local youth mental health services was significantly associated with length of time working as a school psychologist/counsellor, $\chi 2(16)=28.64, p=.026$. That is, school psychologists who were more experienced were more likely to view collaborating with local youth and mental health services as not applicable. Similar to actual collaboration levels, school psychologists/counsellors who worked in Catholic schools believed that they should collaborate more fully with principals compared with independent and government schools, $\chi 2(4)=17.14, p=.002$. Moreover, those who worked in $1-2$ schools also believed that school psychologists/counsellors should more fully collaborate with principals compared with those who worked in three or more schools, $\chi 2(6)=13.98$, $p=.030$.

The number of schools that a school psychologist/counsellor works in was also significantly associated with views on preferred collaboration with school leadership, $\chi 2(9)=25.99, p=.002$. School psychologists/counsellors who worked in one school 
believed that they should be fully collaborating with school leadership more than those who worked in two or more schools.

Furthermore, the level to which school psychologists/counsellors should collaborate with teachers was significantly associated with school sector, $\chi 2(6)=13.80$, $p=.032$, work status, $\chi 2(3)=11.54, p=.009$, and the age of the psychologist/counsellor, $\chi 2(12)=23.89, p=.021$. In particular, those school psychologists/counsellors who worked in Catholic schools believed they should be collaborating more fully than those who worked in independent or government schools, as did those psychologists/counsellors who worked part time compared with full time and those who were aged 50 years and above compared with those who were aged between 20 and 50 years. Lastly, school psychologists/counsellors working in regional areas believed that they should be collaborating more deeply with local youth mental health services as well as local public hospital child and adolescent mental health services than those working in metropolitan areas.

\section{School Psychologists' and Counsellors' Experiences and Attitudes Toward Collaboration}

To investigate school psychologists/counsellors' experiences and attitudes toward collaboration in schools, open-ended questions were included in the survey that asked respondents to describe the barriers and drivers of engaging in collaborative practices. All 42 school psychologists/counsellors responded to this section of the survey. Basing our analysis on Braun and Clarke's (2006) guide for thematic analysis in the psychological sciences, responses were grouped according to question, and codes were generated through an inductive approach that were cross-checked by the research team and then collapsed into themes, reviewed by the research team and chosen. Final themes arising from this analysis are presented below.

\section{Drivers of Collaboration}

Respondents were asked to reflect on the services and professionals that they rated as having full collaboration with and to identify what they believe was the main driver that contributed to these successful collaborations. Themes arising from this question included (in order of frequency): the mutual sharing of information, safety in common values, regular and structured meetings, and mutual respect and role congruence.

Mutual knowledge, information and resource sharing. Approximately 33\% of school psychologists/counsellors' responses included content that showed full collaboration was driven by open communication, honest sharing of ideas and knowledge, advicegiving and sharing resources:

We take opportunities to debrief, share ideas and resources, and programs. We also reflect on organisational concerns and how we can support teachers, how we can be catalysts for change within the organisation.

Common value base that ensures collaboration is done safely. Responses that encapsulated shared professional values across services was said to drive effective collaboration in approximately $26 \%$ of responses. By sharing core attitudes and goals around maintaining student wellbeing, school psychologists/counsellors reported that professionals would agree to work together to support students' needs: 
Principle - respectful of each other's professional expertise and we are both willing to be guided by this; share a common value base with regard to social and emotional concerns for students.

Regular structured team meetings. As service collaboration involves input from a variety of professionals, 19\% of school psychologists/counsellors listed regular team meetings as a key driver of full collaboration. Regular meetings between the school psychologist/counsellor and the pastoral care team, special needs team, learning support teachers, mental health units of a local hospital, and the local youth mental health service were all listed as examples of current collaborative partnerships:

Each person uses their professional strengths to improve service to students. Frequent meetings with clear agenda and appropriate input from all. Clear goal settings and frequent follow up. Process of review and response is undertaken.

Mutual respect and role congruence. Almost 17\% of comments from school psychologists related to the theme of mutual respect and that such respect was paramount to successful collaboration. This was often in conjunction with open communication, regular meetings and shared values. Respecting each other's ideas was also integral to effective collaboration, along with respectful attitudes towards students and each other:

I fully collaborate with the other guidance counsellors (GC) in the school. It works because: we understand the GC role, we meet regularly, we communicate easily and freely with each other, we respect and understand each other's expertise, we are all friendly and easy to work with.

\section{Barriers to School Collaboration}

Content related to barriers to collaborative practice were grouped into the following six themes (in order of frequency): time restrictions, a lack of access to the service or service providers, collaboration not being a priority for the other party, role incongruency, and ethical practices.

Time restrictions. School psychologists/counsellors reported that there was often insufficient time to appropriately collaborate with services, with $35 \%$ of the responses addressing this. Time restrictions were reported to occur both ways; that is, sometimes the other party had no time to collaborate or the school psychologist/counsellor was too busy. Some noted that this was particularly an issue if they worked part time or for several schools:

Time restrictions - workload provides little capacity to identify opportunities and develop stronger relationships, particularly with outside service providers.

Lack of access to the service or service providers. Twenty percent of comments from school psychologists/counsellors included content that revolved around the desire and need to collaborate, but that they faced practical difficulties that stopped them from doing so. Content included: restrictive intake criteria that prevented a student from accessing a service, services being unavailable to assist students with their needs, and lack of funding to pay for services. One school psychologist/counsellor commented 
about the experience of attempting to collaborate with a local youth mental health service:

Barriers included lack of informed consent procedures, time to collaborate, ease of access to contact and discuss cases etc.

Collaboration not being a priority for the other party. Approximately $13 \%$ of responses stated that external school services lacked time and availability for appropriate collaboration with school psychologists/counsellors. Moreover, when the school psychologist instigated collaboration, there was sometimes a lack of response from the other parties who did not prioritise the same cases:

Sometimes it is difficult to collaborate fully with police in relation to child protection matters. They are too busy, or their feedback is that the issue we are concerned about (e.g., physical assault by a parent where there are not visible bruises but child reports it is significant and happens often) is not at the top end of serious concerns for them. Sometimes they seem to be dismissive of our concerns and are not interested in (or do not have time for) full collaboration.

Lack of understanding of school psychologist's/counsellor's role. Similarly, around 13\% of responses conveyed the message that other professionals and services did not always understand the school psychologist/counsellor's role, which often led to a poor understanding of their shared responsibilities. Moreover, this could be compounded by a lack of appreciation and not valuing the expertise of the school psychologist/counsellor:

Information is given where no collaboration is done and follow-up is not discussed. Other service working in isolation and not identifying the importance of school in supporting this student on a day-to-day basis. Misunderstanding by other party about the importance of collaboration and the need for the guidance counsellor to have a clear picture in order to coordinate service in school and monitor student's progress.

Differing professional and ethical practices. Ten percent of comments related to concerns about differing expectations related to the confidentiality of information sharing and student informed consent. One school psychologist reported that high staff turnover in the external agency and overly 'secretive' practices were barriers to deeplevel collaboration:

Barriers are constant change of staff - no person to deal with; unnecessary level of secrecy around outcomes which directly impact students and staff at the school level; limited knowledge of situation of student due to restrictive and irrelevant confidentiality rulings.

Perceived Student Outcomes of Service Collaboration

School psychologists/counsellors were also asked to report on how they believe collaborative school counselling practices have an impact on student outcomes. The responses were all positive in this regard, with $100 \%$ of respondents reporting that there they believed there were improved outcomes for students when a collaborative approach was taken. All stated that professional collaboration leads to improved understanding of students' needs among service providers and resulted in more holistic, effective and efficient support. 
More holistic, effective and efficient support. The most common theme (45\%) related to content that revealed school psychologists/counsellors' belief that greater collaboration among services leads to improved understanding of students' needs, more holistic approaches, and better support of students in all aspects of care. Many stated that collaboration resulted in earlier intervention and improved outcomes in a variety of domains:

The collaborative approach often means a more holistic, effective and efficient outcome for all parties involved in the case, especially when someone else may have helpful information that pertains to the person or the situation/condition.

Improved understanding of students and their needs. Twenty-eight percent of school psychologists/counsellors reported that greater collaboration was related to better student outcomes, especially because it promoted greater understanding of the complex issues that often surrounded or were integral to a student client and their family. Respondents believed that collaboration generated a better understanding of a student's core issues and assisted with making effective referrals to appropriate support:

Students are more likely to have their emotional and social needs appropriately attended to as a collaborative approach broadens the expertise that is being brought to this work.

Better coordination of services. Similarly, approximately $28 \%$ of comments from school psychologists/counsellors referred to more coordinated service delivery when deep collaboration was apparent. Using similar strategies, and having open, regular communication often facilitated greater teamwork. This allowed efficient service delivery without any overlaps as well as a greater subjective experience of the service providers due to strengthened relationships and reduced stress:

Greater collaboration leads to streamlining and focused interventions, better outcomes and stronger relationships with service providers.

Key Ingredients of Effective Collaboration

School psychologists/counsellors were asked: 'Is there anything that school counsellors need to be particularly mindful of when working in a collaborative way with other services or professionals to support students?' Respondents' ideas on the key ingredients for effective collaboration included: ensuring confidentiality of student information is maintained, promoting good relationships with service providers, and ensuring collaboration is student-centred.

Ensuring confidentiality of student information is maintained. Responses related to ensuring confidentiality of student information is maintained was the most common theme, representing $60 \%$ of all comments. The majority of school psychologists/counsellors noted confidentiality as a major issue requiring attention in any type of collaborative information sharing arrangement. Many respondents reported that services need to be aware of the boundaries of information sharing and their professional and legal obligations. It was noted that sensitive information should be handled with care, while respecting the rights of students and families:

Confidentiality - balancing what is in the best interest of the client with regard to sharing information. Able to be discreet and handle things with careful forethought and sensitivity. 
Promoting good relationships with service providers. Working to ensure strong relationships exist between schools and services was the second most cited key ingredient of effective collaboration. It was reported in $20 \%$ of responses that ongoing and clear communication between professionals is necessary for collaborative practice and effective student outcomes:

It takes time to build relationships with other professionals, and this takes energy and lots of conversations. School counsellors need to be willing to set up meetings with other services, to invite them into the school, to have discussions by phone or email.

Student-centred collaboration. Seventeen percent of school psychologists/counsellors spoke about the need of all parties to put the needs of students first when engaged in collaborations:

The student remains at the centre of this work and determines who is involved in the collaboration (if professionally appropriate). Rapport and trust are fundamental to the establishment of a counselling relationship with a student - working collaboratively without student consent can impact on this and the work trying to be achieved.

\section{Discussion}

In Australia, policies such as the Better Outcomes in Mental Health Care initiative have been the impetus for improved collaboration between medical practitioners and psychologists (Hickie \& Groom, 2002). There is also a growing literature within the health and human services domain on the client-outcome benefits of collaboration (i.e., Flatau et al., 2013) and on the 'structure' or mechanics of collaboration, including the development of tools to determine the extent, scope and depth of collaborative practices (i.e., Browne et al., 2004). However, within the education context, overarching policies that promote collaboration between school psychologists and community mental health, health, justice and human services professionals are yet to occur. Similarly, there is a gap in research that evaluates both the qualities, benefits, and effectiveness of within-school and between-school and external services/professionals' collaboration for school psychologists (Kinchin et al., 2016). This is despite there being known benefits for providing integrated services to people with complex needs, including young people (i.e., Bassilios et al., 2017). Yet stakeholder information sharing and confidentiality concerns are repeatedly being cited as dilemmas facing school psychologists and school counsellors alike (i.e., Bell \& McKenzie, 2013; Grubbs, Muro, \& Clements, 2016).

Albeit with a limited sample size, and only in one Australian state, the principle aim of the current study was to begin the process of including school psychological services in theoretical discussions about the benefits of collaborative and integrated practices to support children and young people's psychosocial and educational outcomes. That is, to place school psychologists into the essential mix of services that is available to young Australians who are experiencing comorbid or multi-domain and/or multiservice issues. School psychologists are multi-specialists (O'Dea, King, Subotic-Kerry, O'Moore, \& Christensen, 2017) and work at the coalface of youth mental health, so it is concerning that they are often precluded from research that attempts to encapsulate the range of mental health support services available to children and youth.

On the whole, school psychologists and counsellors in this sample engaged in collaborative practices. They collaborated mostly with professionals from within their 
school, and the professional they collaborated most fully with was the school social worker. This may be a further reflection of the systemic issues that were experienced by their student clients. Their level of collaboration with external services and professionals was limited, although most believed that they should be collaborating at a deeper level with external services.

There were some school-sector differences that received significant findings; however, these findings need to be interpreted with caution due to the small sample size and small numbers representing each school sector, especially in the government sector group. In the current sample of 42 school psychologists and counsellors, those working in Catholic schools were found to collaborate significantly more fully with principals, social workers and teachers than their non-Catholic school counterparts. Furthermore, the current sample of Catholic-sector school psychologists and counsellors also desired greater collaboration with others within and outside of their school than non-Catholic-sector respondents. While this finding is in contrast to previous findings of Victorian school psychologists that revealed no difference in the level of collaboration activities undertaken by school psychologists from each of the three education sectors (Thielking, 2006), further research that explores whether and why school-sector differences in levels of collaboration is warranted. Such research would identify what is particular about the respective sectors that promote or prevent collaborative practices, which would be helpful in developing empirical guidelines for integrated school psychological practice models. Of particular interest would also be the comparison between the level of collaboration between school-employed psychologists, externally contracted school psychologists, and the newly emerging workforce of co-located school psychologists, such as headspace school psychologists.

There were differences in levels of collaboration based on school psychologists' and counsellors's levels of experience and employment circumstances and this points to the significance of resourcing as being an important factor in whether or not professionals engage in collaborative practices. For example, collaboration with the school principal occurred more for school psychologists and counsellors who were more experienced, worked in fewer schools, and who were employed full time. Furthermore, the fewer the schools that respondents worked in, the higher the level of collaboration across the board, with those in fewer schools also endorsing a model of practice that included collaboration with the school principal more fully. This finding provides emerging empirical evidence of the advantages of schools and school systems meeting the APS recommended school psychologist to student ratio of 1:500 (APS, 2016), resulting in closer working relationships between school psychologists, the principal, teachers and other stakeholders.

The finding that school psychologists and counsellors in metropolitan schools had better depth of collaboration scores with school psychologists and counsellors in metropolitan areas than those from regional areas may also be a reflection of resourcing, where there is more opportunity to collaborate with larger school-based mental health teams in metropolitan areas. Alternatively, regional school psychologists and counsellors believed they should be collaborating with local youth mental health services at a significantly deeper level than non-regional respondents - perhaps also a reflection of service availability. This finding has implications for the training of educational and developmental psychologists who are intending to work in schools in regional areas, especially with regard to ensuring these school psychologists are equipped to work in multidisciplinary teams in order to reduce isolation and burnout. 
Qualitative feedback revealed that school psychologists and counsellors believed that the drivers of collaborative practice included mutual sharing of information, safety in common values, regular and structured meetings, and mutual respect and lack of understanding of school psychologist's and counsellor's role. Noted barriers included time restrictions, a lack of access to the service or service providers, collaboration not being a priority for the other party, role incongruency, and differing professional and ethical practices. Some of these barriers are also reflected in the literature, particularly the issue of needing to carefully manage confidentiality when engaging in information sharing (Campbell \& Colmar, 2014).

Strong relationships between service providers was seen as an important component of deep collaborative practices for respondents. The need to establish mutual and respectful working relationships between service providers is a known key ingredient of effective collaboration (Flatau et al., 2013). Such qualities of effective collaboration promotes a sense of safety in the act of information sharing between service providers. School psychologists and counsellors believed that if done ethically, students benefitted significantly from collaborative practices. They believed that such an approach to service delivery would ensure timely services are provided that meet the full needs of students in a holistic way. This is the driving theory behind the promotion of service integration policy in the health and human services arena - that better integration results in better patient outcomes (Browne et al., 2004).

When commenting on the key ingredients of effective collaboration, respondents also shared their concerns around what could go wrong when information sharing occurs without student consent or when confidentiality is not maintained. It was absolutely vital for school psychologists and counsellors in this study to be able to trust that that there was a 'two-way' professional understanding of how information can be shared and that the wellbeing of students was always at the centre of collaborative practice.

The educational and developmental psychology profession can gain insights from cross-disciplinary research on the mechanisms and advantages of service integration in the health and human services sector. School psychologists would benefit from further discipline-specific research that both informs and advances a more systemically connected Australian school psychology workforce. School psychologists provide an important service within the wider system of support services available to children, young people and their families. A guiding framework for collaborative school psychological service delivery, with full recognition of the ethical responsibilities of this profession, would also assist to alleviate the tensions that are often created when school psychologists must choose between the need to maintain client confidentiality and the desire to work with others who are also involved in the student-client's care.

\section{Conflicts of Interest}

None.

\section{Ethical Standards}

The authors assert that all procedures contributing to this work comply with the ethical standards of the relevant national and institutional committees on human experimentation and with the Helsinki Declaration of 1975, as revised in 2008. 


\section{References}

Adelman, H.S., \& Taylor, L. (2002). School counselors and school reform: New directions. Professional School Counseling, 5, 235-248. Retrieved from http://web.a.ebscohost.com.ezproxy.lib.swin.edu.au/

Australian Psychological Society (APS). (2007). APS code of ethics. Melbourne, Australia: Author. Retrieved from https://www.psychology.org.au/Assets/Files/APS-Code-of-Ethics.pdf

Australian Psychological Society (APS). (2016). The framework for effective delivery of school psychology services: a practice guide for psychologists and school leaders. Retrieved from http://www.psychology.org.au/Assets/Files/School-psych-services.pdf

Bassilios, B., Rickwood, D., Pirkis, J., Spittal, M.J., \& Telford, N. (2017). Complementary primary mental health programs for young people in Australia: Access to Allied Psychological Services (ATAPS) and headspace. International Journal of Mental Health Systems, 11, 1-11.

Bell, H.D., \& McKenzie, V. (2013). Perceptions and realities: The role of school psychologists in Melbourne, Australia. Australian Educational \& Developmental Psychologist, 30, 54-73. doi:10.1017/edp.2013.1

Braun, V., \& Clarke, V. (2006). Using thematic analysis in psychology. Qualitative Research in Psychology, 3, 77-101. doi:10.1191/1478088706qp063oa

Browne, G., Roberts, J., Gafni, A., Byrne, C., Kertyzia, J., \& Loney, P. (2004). Conceptualizing and validating the human services integration measure. International Journal of Integrated Care, 4, 1-12. doi:10.5334/ijic. 98

Campbell, M., \& Colmar, S. (2014). Current status and future trends of school counseling in Australia. Journal of Asia Pacific Counseling, 4, 181-197. doi:10.18401/2014.4.2.9

Family and Community Services. (n.d.). Keep Them Safe and interagency collaboration. Sydney, Australia: NSW Government. Retrieved from http://www.community.nsw.gov.au/kts/collaboration

Faulkner, M., \& Jimerson, S.R. (2017) National and international perspectives on school psychology: Research, practice and policy. In M. Thielking \& M. Terjesen (Eds.), Handbook of Australian school psychology (pp. 1-19). Cham, Switzerland: Springer. doi: https://doi.org/10.1007/978-3-31945166-4_1

Flatau, P., Conroy, E., Thielking, M., Clear, A., Hall, S., Bauskis, A., Farrugia, M., \& Burns, L. (2013). How integrated are homelessness, mental health and drug and alcohol services in Australia? (Report no. 206). Melbourne, Australia: Australian Housing and Urban Research Institute.

Gerry, M.H., \& Paulsen, R. (1995). Building community-based networks of children's services and family supports. New York, NY: Aspen Institute.

Gilligan, R. (1998). The importance of schools and teachers in child welfare. Child \& Family Social Work, 3, 13-25. doi:10.1046/j.1365-2206.1998.00068.x

Glosoff, H.L., \& Pate Jr., R.H. (2002). Privacy and confidentiality in school counseling. Professional School Counseling, 6, 20-27.

Goodwin, N. (2008). Are networks the answer to achieving integrated care? Journal of Health Services Research and Policy, 13, 58-60. doi:10.1258/jhsrp.2008.008001.

Grone, O., \& Garcia-Barbero, M. (2002). Trends in integrated care: Reflections on conceptual issues (Report No. EUR/02/5037864). Copenhagen, Denmark: World Health Organization.

Grubbs, L., Muro, J. H., \& Clements, K. (2016). School counselors and nurses: Collaborative best practices for maintaining confidentiality with pregnant adolescents. The Practitioner Scholar: Journal of Counseling and Professional Psychology, 5, 20-31.

Health Records Act 2001 (Vic). Retrieved from https://www2.health.vic.gov.au/about/legislation/healthrecords-act

Hickie, I., \& Groom, G. (2002). Primary care-led mental health service reform: An outline of the Better Outcomes in Mental Health Care initiative. Australasian Psychiatry, 10, 376-382. doi:10.1046/j.1440-1665.2002.00498.x

Hobbs, B.B., \& Collison, B.B. (1995). School-community agency collaboration: Implications for the school counselor. School Counselor, 43, 58-65.

Hudson, P.B. (2012). A model for curricula integration using the Australian curriculum. Teaching Science, $58,40-45$. Retrieved from http://search.proquest.com.ezproxy.lib.swin.edu.au/docview/ 
Keast, R., Brown, K., \& Mandell, M. (2007). Getting the right mix: Unpacking integration meanings and strategies. International Public Management Journal, 10, 9-33. doi:10.1080/10967490601185716

Kinchin, I., Tsey, K., Heyeres, M., \& Cadet-James, Y. (2016). Systematic review of youth mental health service integration research. Australian Journal of Primary Health, 22, 304-315. doi:10.1071/py15114

Lawrence, D., Johnson, S., Hafekost, J., Boterhoven De Haan, K., Sawyer, M., Ainley, J., \& Zubrick, S.R. (2015). The mental health of children and adolescents: Report on the second Australian child and adolescent survey of mental health and wellbeing. Canberra, Australia: Department of Health.

McArthur, M., Thomson, L., Winkworth, G., \& Butler, K. (2009). Getting what we need: Families'experiences of services. Report for the Department of Families, Housing, Community Services and Indigenous Affairs. Canberra, Australia: Institute of Child Protection Studies, Australian Catholic University.

Nicholson, D., Artz, S., Armitage, A., \& Fagan, J. (2000). Working relationships and outcomes in multidisciplinary collaborative practice settings. Child \& Youth Care Forum, 29, 39-73. Retrieved from http://search.proquest.com.ezproxy.lib.swin.edu.au/

O’Dea, B., King, C., Subotic-Kerry, M., O'Moore, K., \& Christensen, H. (2017). School counselors' perspectives of web-based stepped care mental health service for schools: Cross-sectional online survey. JMIR Mental Health, 4, e55. doi:10.2196/mental.8369

Pirkis, J., Stokes, D., Morley, B., Kohn, F., Mathews, R., Naccarella, L., .. Burgess, P. (2006). Impacts of Australia's better outcomes in mental health care program for psychologists. Australian Psychologist, $41,152-159$.

Privacy Act 1988 (Commonwealth). Retrieved from https://www.oaic.gov.au/privacy-law/privacy-archive/ privacy-resources-archive/privacy-fact-sheet-2-national-privacy-principles

Power, S., Whitty, G., \& Youdell, D. (1999). Doubly disadvantaged: Education and the homeless child. In P. Vostanis \& S. Cumella (Eds.), Homeless children: Problems and needs (pp. 130-141). London, England: Jessica Kingsley Publishers.

Reid, W. (1996). School counselling: A client centred perspective. Brisbane, Australia: Kids Help Line.

Safran, S.P., \& Oswald, K. (2003). Positive behavior supports: Can schools reshape disciplinary practices?. Exceptional Children, 69, 361-373. doi:10.1177/001440290306900307

Scott, E., Naismith, S., Whitwell, B., Hamilton, B., Chudleigh, C., \& Hickie, I. (2009). Delivering youthspecific mental health services: The advantages of a collaborative, multidisciplinary system. Australasian Psychiatry, 17, 189-194. doi:10.1080/10398560802657322

Scruggs, T.E., Mastropieri, M.A., \& McDuffie, K.A. (2007). Co-teaching in inclusive classrooms: A metasynthesis of qualitative research. Exceptional Children, 73, 392-416. doi:10.1177/001440290707300401

Thielking, M. (2006). An investigation of attitudes towards the practice of school-based psychological services (Doctoral dissertation, Swinburne University of Technology, Melbourne, Australia). Retrieved from http://hdl.handle.net/1959.3/38889

Thielking, M., \& Jimerson, S.R. (2006). Perspectives regarding the role of school psychologists: Perceptions of teachers, principals, and school psychologists in Victoria, Australia. Australian Journal Of Guidance And Counselling, 16, 211-233.

Williams, P., \& Sullivan, H. (2009). Faces of integration. International Journal of Integrated Care, 9, 1-13. 